\title{
Uusi andmeid Äänisjärve Oleni saare skulptuuride kohta
}

Tatjana Popova

Kirde-Euroopa mesoliitikumi mälestiste hulgas on eriline koht Karjalas Äänisjärve Lõuna-Oleni saarel asuval kalmistul. Meenutagem, et see avastati 1936. aastal paekarjääri kaevandustööde käigus, mis kalmistut märgatavalt rikkus. Aastail 1936-1938 viis professor V. Ravdonikase juhitav ekspeditsioon mälestisel läbi ulatuslikud väljakaevamised (Ravdonikas 1940; Žirov 1940).

1939. aastal anti väljakaevamiste materjalid üle Peeter Suure nimelise Venemaa Teaduste Akadeemia Antropoloogia ja Etnograafia Muuseumile (Kunstkamera), kus neid tänini säilitatakse Venemaa nii arheoloogia kui ka Kunstkamera tõeliselt hindamatu kullafondina. ${ }^{1}$

Selle varaholotseeniaegse silmapaistva nekropoli ebatavalised arheoloogilised (Ravdonikas 1956; Gurina 1956) ja paleontoloogilised materjalid (Debets 1948; Gurina 1956; Jakimov 1960) on ammu saanud maailmakuulsaks ja on teaduslikus ringluses.

Viimastel aastakümnetel on leitud arvukalt huvitavaid mesoliitilisi ja neoliitilisi asulakohti Venemaa Euroopa-osa põhja- ja väheuuritud kirdepiirkondades (Pankrušev 1978; Ošibkina 1983; Filatova 1988), samuti on avastatud neli uut mesoliitilist kalmistut: Karjalas Sjamozerski II, Tšjornaja Guba I ja Äänisjärve idaosas Pestšanitsõja, Popovo (Ošibkina 1982, 1989; Gurina 1989; Gohman 1984).

Enamgi veel, praeguseks on kindlaks tehtud, et Oleni saare kalmistu, mille V. Ravdonikas ja N. Gurina dateerisid III-II aastatuhandesse eKr (Ravdonikas 1956), kuulub uute radioaktiivse süsiniku meetodil põhinevate uuringute kohaselt VI aastatuhande teise poolde või V

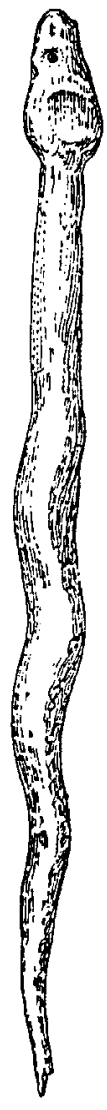
aastatuhande algusesse eKr (Mamonova \& Suleržitski 1989). Oxfordi laboratoorium on määranud kalmistu

Joonis 1. Mao kujutis (matmiskoht nr 23).

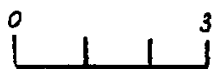


päritolu veelgi varasemasse aega - VI aastatuhande keskpaik eKr (Price \& Jacobs 1990). Mälestise vanuse osas ei ole seni üksmeelt saavutatud, ent suurem osa uurijaid seostab kalmistut mesoliitikumiga. Uusi $\mathrm{C}^{14}$ põhinevaid andmeid ei tunnista kõik uurijad, osa neist peavad kalmistut endiselt neoliitiliseks (Alekšin 1994).

Oleni saare kalmistut on käsitletud mitmes laiemat küsimusteringi puudutavas uurimuses (Lauškin 1962; Masson 1976; Stoljar 1983), sh neis, mis puudutavad Äänisjärve piirkonna iidsete hõimude matmiskombestiku tüüpe ja eripära ning omapäraseid luust ja sarvest muinasaja kunstiesemeid.

Oleni saare kalmistu paistab samaaegsete mesoliitikumi mälestiste seas silma hauapanuste rohkuse ja spetsiifika poolest. Ta on ainulaadne ja mõneti mõistatuslik mälestis Kirde-Venemaal ja Skandinaavia poolsaarel. Seetõttu pole juhuslik, et huvi Oleni saare muistise kui arheoloogilise võtmeallika vastu ei rauge, vaid muutub uurimistaseme arengu ja uute lähenemisviiside tõttu üha ligitõmbavamaks (Ošibkina \& Krainov \& Zimina 1992; Stoljar 1994, 1995; Popova 1995).

Suurte kiltkivist, kvartsist ja ränikivist hauapanuste kõrval leidub ka orgaanilisest ainest, põdra-, ulukpõhjapõdra-, hundi-, karu- ja kopraluust ning sarvest valmistatud jahi-ja kalapüügivahendeid, relvi ja ehteid (plaadid ja ripatsid).

Eriti huvitavad on esmaklassilised luust ja sarvest esiajaloolised kunstiteosed, mis iseloomustavad Äänisjärve iidsete kalameeste ja küttide vaimset maailma. Hiljuti avastati matusest nr 23 pärinevalt luust maoskulptuurilt (joonis 1) kaks uut kujutist. Ühe leidis tartlane V. Poikalainen, kes pildistamisel avastas mao peas antropomorfse (näo-)kujutise. Teatud rakursi all ja sobivas külgvalguses oli see hästi eristatav (joonis 2). Ülalt kergelt kühmus ja alt lapikus maopeas asuvad väikesed ümarad lohud - mao silmad (Gurina 1956) muutusid inimnäo silmadeks ja vaevunähtava süvendi suuks, mille toel joonistus omakorda üsna hästi välja nina.

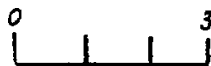

Joonis 2. Antropomorfne kujutis (nägu). 


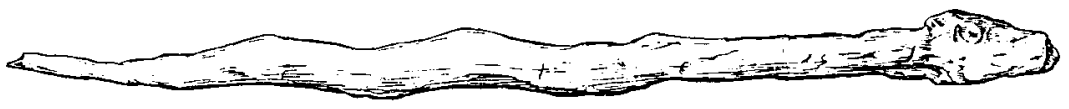

Joonis 3. Põdra kujutis.

Pärast sellist sensatsioonilist leidu naasti uuesti taiese juurde. Hoolikal vaatlemisel selgus, et esemel on eristatav veel kolmaski kujutis, samuti pea piirkonnas. See asub mao ja inimese kujutise vastasküljel, s.o külgvaates ning varem polnud keegi seda märganud (joonis 3). Kujutatud on põdra pead tema iseloomulike tunnustega: looma pea on piklik, selle ots paksendatud, rõhutatud on iseloomulikku lõuaalust osa "habet", väikesed kõrvad on surutud vastu kaela, suud tähistab ümar, vaevumärgatav süvendjoon. Väljendusrikas on silm - mitte süvend, vaid ümmargune mügar (silm ja laug). Põdra kujul on ka individuaalsed tunnused, mis on iseloomulikud kõigile Oleni saare kalmistu põdrapeadele. Kuigi kujutised üksteisest ühel või teisel määral erinevad, on looma, sõltumata suurusest ja materjali lihvimise maneerist, alati kujutatud külgvaates.

Selle uue põdrakujutise vahetuid analooge leiame ka kalmistu muude leidude seas. Näiteks luust nikerdatud pea matusest nr 82 (Gurina 1956), aga ka luust jahimehekinžalli matusest $\mathrm{nr} 61$, mille käepideme kaunistuseks on põdrapea (ibid).

Maokujuke on valmistatud looma toruluust ja selle pinnal on õrnad poleerimisjäljed. See kujutab roomajat koos pea ja kehaga. Kujukese pikkus on $17,6 \mathrm{~cm}$. Seejuures moodustab looklev keha $2 / 3$ kogupikkusest. Ülejäänud $1 / 3$ on vertikaalasendis vaadeldav antropomorfse iidoli kaela ja ülakehana, horisontaalasendis võib aga ära tunda põdra. On tähelepanuväärne, et iidne nikerdaja on oskuslikult kujundanud mao iseloomulikult esiletungivat lõualuukaart ja kõri, rõhutades sellega ühtlasi põdra pead ja kaela.

Kalmistult on pärit veel üks maokujuke, mis on leitud naise matusest $\mathrm{nr} 57$ vasaku õlaluu piirkonnast: tegemist on rikkalike panustega kolmikhauaga nr 55-56-57. Ka see on nikerdatud looma toruluust ja selle pinnal on säilinud intensiivse lihvimise jäljed. ${ }^{2}$ Pea on kaduma läinud. See ese erineb esimesest kujust mitte niivõrd selle poolest, et ta on lühem $(12 \mathrm{~cm})$ ja looklevama kerega, kuivõrd selle poolest, et seda pole töödeldud ruumiliselt nagu esimest, vaid bareljeefina, see tähendab, et selle üks külg on lame (joonis 4). Muidugi oli sellel kujukesel teine otstarve: kõige tõenäolisemalt kasutati seda fiksaatorina millegi kinnitamiseks, võimalik, 


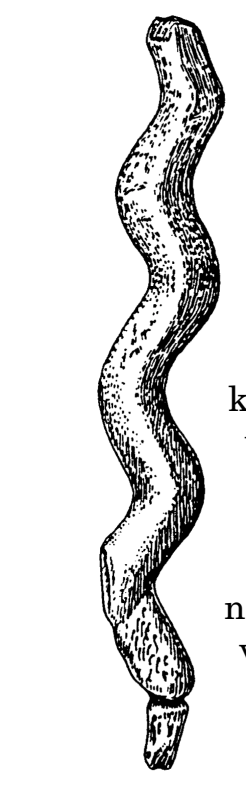

et see oli mingi teise eseme aplikatsiooniks. Viimast lubab oletada sabaosas asuv sügav sisselõige (Gurina 1956).

Oleni saare kalmistu leid, kus inimene ja põder on kujutatud ühenduses maoga, lubavad oletada, et see pole üksnes muinastaide sünkretismi ere näide. Antud juhul on tegemist kahtlemata erilise kultusesemega, millesse on kodeeritud kolm erinevat ikonograafilist kujutist. Matuse $\mathrm{nr} 23$ sellele ofidio-antropo-zoomorfsele kujutisele ei teata kusagil olevat analooge.

Usutavasti on tegemist püha põdraga, kes oli kunagiste Oleni saare asukate soosikloom. Ta oli metsa valitseja, selle peremees, kes tagas jahiõnne. Ta on ühendatud antropomorfse iidoliga, keda võib etnograafiliste paralleelide põhjal oletamisi seostada esivanema, perekonna kaitsjaga. Sel-

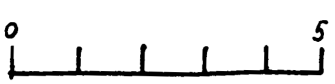

liste iidolite poole pöördutakse tavaliselt rasketel hetkedel, lootes neilt kaitset ja abi. Puust, sarvest ja teistest orgaanilistest materjalidest iidolid on üsna levinud näiteks paljudel Siberi põlisrahvastel. Sellega seoses pakuvad huvi A. Anissimovi tähelepanekud Põhja-Jenissei evenkidest, kes eristasid perekonna ja sugukonna kaitsjaid, kusjuures perekonna kaitsjaid kujutati antropomorfsetena, sugukonna kaitsjaid aga zoomorfsetena (põder, karu jt) (Anissimov 1950).

Raskem on selgitada mao funktsiooni. Eitamata maokultuse olemasolu ja järvepiirkonna iidsete rahvaste austust tema vastu, on olemasolevatele andmetele tuginedes raske kuulutada teda ühetähenduslikult viljakuse sümboliks (Gurina 1956). Pole välistatud, et antud juhul kannab madu ktooniliste jõudude tähendust, ning seotuna alumise, sealpoolse maailmaga on ta maa- ja veealuse kuningriigi esindaja.

Uute andmete valguses peame kohaseks meenutada ka matusest $\mathrm{nr} 130$ leitud mehekujutist (Gurina 1956), mida peame antropozoomorfseks. Tähelepanu paeluvad kujukese jalad, mis lõpevad mitte jalalabade, vaid looma, kõige tõenäolisemalt põdra sõrgadega (joonis 5). Teostuselt on nad lähedased Kubenino (matus nr 2) antro- 
Joonis 5. Antropomorfne kujutis (matus nr 130).

pomorfse (õigemini antropozoomorfse) sarvest kujukese sõrgadega jalgadega (Ošibkina \& Krainov \& Zimina 1992). V. Ravdonikas pidas seda mitte antropomorfseks, vaid falliliseks kujutiseks (Ravdonikas 1956).

Üksikasjalikumalt peatume matuse nr 23 teistel huvitavatel leidudel, mis ülaltoodut arvestades pole sugugi vähetähtsad. Väljakaevamiste andmetel oli matmispaika kahjustanud karjääri rajamine. Maetu jalad olid algses asendis, aga ülakeha ja käed olid segi paisatud. Koljut polnud säilinud ja maetu sugu on kindlaks tegemata. Matmissügavus oli 0,5 m (Gurina 1956) ja tegemist on kalmistul kõige sagedamini esineva matmistüübiga. See on üksikmatus, keha on horisontaalselt välja sirutatud, seliliasendis, mitte kuigi sügaval ja - nagu suurem osa kalmistul olevaid haudu - on selle orientatsioon itta tõusva päikese suunas.

Samal ajal eristub nr 23 teistest matustest hauapanuste tavatu vähesusega (Gurina 1956). Puuduvad loomaluude jäänused, see tähendab, et toidumoona teele kaasa ei pan-

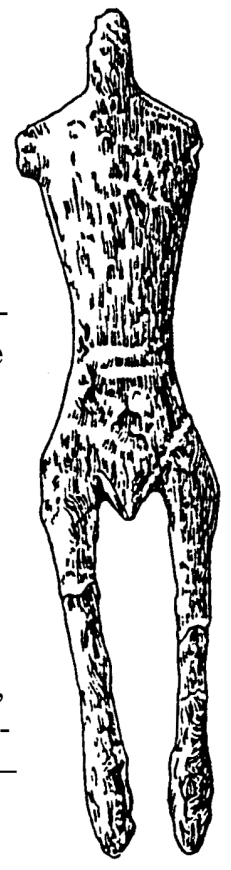
dud. Ehetest on märgitud kopra lõikehammastest kolme plaati, mis olid paigutatud rinnale, ja seitset põdra lõikehammast, mis asusid parema puusa piirkonnas ofidio-antropo-zoomorfse kujukese vahetus läheduses. Huvitav on, et just siit on pärit üks kahest (see ei ole vääratus, kuivõrd kolmandat peame antropozoomorfseks) kalmistul leitud inimfiguurist. Jutt on kahenäolise Januse tüüpi kujukesest (ibid). Võrdlev analüüs näitas, et selle kuju mõlema näo suu on loodud samade tehniliste võtetega nagu antropomorfse näo suu. Ühesugune suu kujutamise maneer on omane ka matusest $\mathrm{nr} 18$ leitud naisekujukesele. Seetõttu võivad kalmistu antropomorfsed kujukesed stilistilises mõttes kuuluda samasse inimese skemaatilise kujutamise tüüpi, kuigi neil on täheldatavad mõningad variatsioonid.

Vaatamata hauapanuste nappusele paistab matus $\mathrm{nr} 23$, nagu ka matused nr 18 ja 130, silma Oleni saare iidsete asukate loodud 
muinastaide väljapaistvate eksemplaridega. Matuse $\mathrm{nr} 23$, muuseas ka nr 130, veel üheks eriliseks jooneks on asjaolu, et haua põhi ja luud on tugevalt ookriga üle puistatud $(0,04 \mathrm{~m}$ paksuselt), mis N. Gurina arvates ei ole väheste panustega matustele tüüpiline.

Haua nr 23 iseloomuliku atribuutikaga seoses tuletame meelde, et uurijad on määratlenud kalmistul kaks kompleksset matmispiirkonda, põhja- ja lõunapiirkond, ning see matus asub lõunapiirkonnas (Gurina 1956). $\mathrm{C}^{14}$ meetodil dateerimine võimaldas sedastada, et algselt asus kalmistu kese põhjapiirkonnas, hiljem laienesid kalmud lõuna suunas (Stoljar 1994, 1995; Ošibkina 1994). Kui vaadelda sellest lähtudes Oleni saare sarv- ja luuskulptuuride kõigi liikide jagunemist matuste kaupa, siis selgub, et põdrakujutised pärinevad põhjapiirkonna kalmetest. Inimkujutisega leiud on omased kalmistu lõunapiirkonna matustele (nr 18, 23). Maokujutisi on leitud kalmistu lõunapiirkonna (nr 23) ja keskosa (nr 57) matustest.

Siit järeldub, et vanem ja domineerivam sümbol on zoomorfne kalmistu varasemast perioodist pärinev põdrakujutis on seostatav põdrakultusega. Selle kõrval oli nekropoli algperioodil olemas ka teine tüüp antropozoomorfseid kujutisi - inimene-põder (matus nr 130). Sel ajajärgul on täheldatav ka juhtide nn eliitmatuste teke (nr 152-153 jt).

Hiljem, kui rajati keskpiirkonna hauad, säilisid zoomorfsed kujutised. Koos sellega levis arvatavasti ka uus kultus: austati uut olendit, madu, mida kinnitab ofidomorfne kujutis (matus nr 57). Edaspidi, lõunapiirkonna kalmete tekkides, ilmuvad uudsed näo detailse töötlusega inimkujud, mis osutab esivanemate kultusele. Maokujutis säilib, kuid mitte iseseisvana. Selle ajajärgu teiseks iseärasuseks on uut tüüpi kujutis - koondkuju, s.t mao, inimese ja põdra koos kujutamine. Viimane, nagu ka inimese kujutis, on iseloomulik ainult lõunapiirkonna matustele, kus ei ole rikkalike panustega kalmeid.

Sugugi vähetähtsad ei ole andmed selle kohta, et kalmistu põhjapiirkonnas on esindatud europiidne antropoloogiline tüüp, aga lõunapiirkonnas on täheldatav mongoliidne. Praegugi oletavad antropoloogid, et Lõuna-Oleni saare kalmistule maetute antropoloogiline koosseis oli heterogeenne ja keeruline. Ühtlasi on I. Gohman uute uuringutega kindlaks teinud, et nekropolis on esindatud peamiselt põhjaeuroopa ja uurali komponentidega antropoloogiline tüüp (G. Debetsi järgi idakromanjoonlane), kellel on lõunaeurooplikke ja siberi mongoliidseid jooni (Gohman 1994). 
Selle alusel võib öelda, et kalmistu lõunapiirkonna matmispaikadel täheldatavad uut tüüpi antropomorfsed kujutised, samuti nagu tavatult polümorfne kujutis, annavad tunnistust rituaali vahetumisest, mis on seotud uue, kõige tõenäolisemalt idast pärineva etnosega. Seda enam, et just lõunapiirkonda on koondunud laponoidsete isikute matused.

Ilmne on maailmavaatelise süsteemi muutumine, mis tõi kaasa kõigi kujundite semantilise välja muutumise. Muutus varasem põdra ja mao austamise traditsioon. Oletatakse, et lõunapiirkonna matusest nr 23 leitud liitkujutisel olev põder tähistab geneetilist mälu. Niisiis võib rääkida viiest Oleni saare skulptuuri tüübist (zoomorfne, antropomorfne, antropozoomorfne, ofidiomorfne ja ofidio-antropomorfne). Kujude valmistamiseks kasutati ainult metsloomade sarvi ja luid, mis eristab neid sama piirkonna varasematest (VII aastatuhat eKr) mälestistest: Veretje kultuuris kasutati ka puitu ja Vis I turbalasundi alt leitud asulas puuduvad luuesemed, on üksnes puust, kasetohust ja puukoorest esemeid ning taimedest punutisi. Oleni saare materjalide seas on olulise tähtsusega Pestšanõ kalmistukompleks (VIII aastatuhande keskpaik eKr) ja eriti Popovo (VII aastatuhat eKr). Mõlemad mälestised on S. Ošibkina omistanud Veretje kultuurile. Nende matmiskombestik ja üksikud leiud demonstreerivad uurijate arvates sarnasust Oleni saare kalmistuga, mis jätkas nende komplekside traditsiooni (Ošibkina 1989). Samal ajal on märgitud, et Veretje ja Oleni saare kultuuri materjalidel leidub pronksiaegseid analooge - Koola lahe Oleni saarel asuva laplaste esivanematega seostatava kalmistu panustes (Schmidt 1930).

Niimoodi avardavad uued, Oleni saare muististe tähendusrikkad elemendid meie ettekujutust muistsete Äänisjärve-äärsete elanike vaimsest kultuurist ja sakraalsfäärist, nende kultustest ja kombestikust, mis teatud mõttes etendas reguleerivat rolli, tagades suurema sootsiumi - mandrielanike ühiskonna - stabiilsuse.

Koos teiste faktidega lubavad need edaspidi avada üksikute nähtuste semantikat teisest aspektist, detailsemalt analüüsida kalastajate ja küttide ühiskonna sotsiaalset struktuuri, täpsustada nende etnilisi juuri. Selles suhtes tundub olevat perspektiivne pöörduda põhja, eelkõige Äänisjärve kaljujooniste süžeede poole, aga ka uurida Euraasia metsavööndi tunduvalt hilisemaid kultuure. 


\section{Kommentaarid}

${ }^{1}$ MAE (Antropoloogia- ja Etnograafiamuuseumi) kogu nr 5716; ühikute arv - 720; esemete arv - 1073 .

${ }^{2}$ Mikroskoopanalüüs näitas, et eseme pinnal on peenpoleerimise kriimud, võimalik, et kasutati ookrit. Matusest nr 23 leitud luust maokujukese pind on samuti lõpetamata töötluse tunnistajaks.

\section{Kirjandus}

Alekšin, V. A. 1994. Datirovka Oleneostrovskogo mogilnika (arheologitšeskije kriterii protiv radiouglerodnõhh dat). Tezissõ dokladov na meždunarodnoi konferentsii, posvjaštšjonnoi 100-letiju so dnja roždenija professora V. I. Ravdonikasa. Sankt-Peterburg.

Anissimov, A. F. 1950. Semeinõje "ohraniteli" u evenkov i problema genezisa kulta predkov. Sovetskaja etnografija 3.

Debets, G. F. 1948. Paleoantropologija SSSR. Trudõ Instituta etnografii SSSR IV.

Filatova, V. F. 1988. Mezolititšeskije pamjatniki Karelii. Poselenija drevnei Karelii. Petrozavodsk.

Gohman, I. I. 1984. Novõje paleoantropologeskije nahhodki epohhi mezolita v Kargopolje. Problemõ antropologii drevnego $i$ sovremennogo naselenija Severa Jevrazii. Leningrad.

Gohman, I. I. 1994. Oleneostrovski mogilnik na Onežskom ozere kak istotšnik rassogeneza naselenija severo-zapada Rossii i Fennoskandii. Tezissõ dokladov na meždunarodnoi konferentsii, posvjaštšjonnoi 100-letiju so dnja roždenija professora V. I. Ravdonikasa. Sankt-Peterburg, lk 53-55.

Gurina, N. N. 1956. Oleneostrovski mogilnik. Materialõ $i$ issledovanija po arheologii SSSR 47. Moskva \& Leningrad

Gurina, N. N. 1989. Mezolit Karelii. Mezolit SSSR. Moskva.

Jakimov, V. P. 1960. Antropologitšeskije materialõ iz neolititšeskogo mogilnika na Južnom Olenjem ostrove. Sbornik Muzeja Antropologii i Etnografii 19. Moskva-Leningrad.

Lauškin, K. D. 1962. Onežskoje svjatilištše. Skandinavski sbornik 5. Tallinn, lk 177-298.

Mamonova, N. N. \& Suleržitski, L. D. 1989. Opõt datirovanija po 14-C pogrebenii Pribaikalja epohhi golotsena. Sovetskaja arheologija 1.

Masson, V. M. 1976. Ekonomika i sotsialnõi stroi obštšestv. Leningrad.

Ošibkina, S. V. 1982. Mezolititšeski mogilnik Popovo na reke Kineme. Sovetskaja arheologija 3.

Ošibkina, S. V. 1983. Mezolit basseina Suhhonõ i vostotšnogo Prionežja. Moskva.

Ošibkina, S. V. 1989a. Mezolit tsentralnõhh i severo-vostotšnõhh rajonov Severa Jevropeiskoi tšasti SSSR. Mezolit SSSR. Moskva, lk 32-45. 
Ošibkina, S. V. 1989b. The material culture of the Veretye-type sites in the region to the east of Lake Onega. The Mesolithic in Europe. Edinburgh.

Ošibkina, S. V. 1994. Mogilniki epohhi mezolita na severe Rossii. Drevnosti lesnoi zonõ Vostotšnoi Jevropõ. Tezissõ dokladov $k$ zasedaniju otdela arheologii Vostotšnoi Jevropõ $i$ Sibiri Gossudarstvennogo Ermitaža, posvjaštšjonnomu 60-letiju so dnja roždenija A. M. Mikljajeva.

Ošibkina, S. V. \& Krainov, D. A. \& Zimina, M. P. 1992. Iskusstvo kamennogo veka (lesnaja zona Vostotšnoi Jevropõ). Moskva.

Pankrušev, G. A. 1978. Mezolit i neolit Karelii 1-2. Leningrad.

Popova, T. A. 1995. Zagadki drevnego Zaonežja (novõje artefaktõ Oleneostrovskogo mogilnika). Drevnosti severo-zapadnoi Rossii. Sbornik materialov nautšnoi konferentsii, posvjaštšjonnoi 90-letiju so dnja roždenija G. P. Grozdilova. Sankt-Peterburg.

Price, T. D. \& Jakobs, K. 1990. Olenii ostrov: first radiocarbon dates from a major Mesolithic cemetery in Karelia USSR. Antiquity 64: 245.

Ravdonikas, V. I. 1940. Neolititšeski mogilnik na Onežskom ozere. Soveršennik arheologija 6.

Ravdonikas, V. I. 1956. Neolititšeski mogilnik na Južnom Olenjem ostrove Onežskogo ozera. Materialõ $i$ issledovanija po arheologii SSSR 47. Moskva-Leningrad, lk 7-24.

Stoljar, A. D. 1983. "Žezlõ" onežskihh petroglifov i ihh materialnõje prototipõ. Izõskanija po mezolitu i neolitu SSSR. Leningrad, lk 145-158.

Stoljar, A. D. 1994. Transljatsija idei kak mnogoobraznaja arheologitšeskaja realnost (po mezo-neolititšeskim materialam severo-zapada jevropeiskoi Rossii). Kulturnõje transljatsii i istoritšeski protsess (paleolit sredenevekovije). Sankt-Peterburg.

Stoljar, A. D. 1995. Oleneostrovski mogilnik i ego pogrebenije No. 100 kak agentõ mezolititšeskogo etnokulturogeneza Severa. Drevnosti severozapadnoi Rossii. Sbornik materialov nautšnoi konferentsii, posvjaštšjonnoi 90-letiju so dnja roždenija G. P. Grozdilova. Sankt-Peterburg, lk 16-22.

Šmidt, A. V. 1930. Drevni mogilnik na Kolskom zalive. Kolski sbornik.

Žirov, E. V. 1940. Zametka o skeletahh neolititšeskogo mogilnika Južnogo Olenjego ostrova. Kratkije soobštšenija Instituta Istorii Materialnoi Kulturõ 6. Moskva. 